\title{
Does Being Gritty Mean Being College-Ready? Investigating the Link between Grit and College Readiness among Filipino K-12 Graduates
}

\author{
Febe Marl G. Paat, Antonio I. Tamayao, Rudolf T. Vecaldo \\ Maria T. Mamba, Jay Emmanuel L. Asuncion and Editha S. Pagulayan \\ Cagayan State University, Tuguegarao City, Province of Cagayan, Philippines \\ https:// orcid.org/0000-0003-2290-4548 \\ https:// orcid.org/0000-0003-2720-2641 \\ https:// orcid.org/0000-0003-1723-3487 \\ https:// orcid.org/0000-0002-6676-6151 \\ https:// orcid.org/0000-0003-0701-5689 \\ https:// orcid.org/0000-0003-2066-3808
}

\begin{abstract}
This study challenges the basic assumption that college readiness is accounted to senior high school (SHS) graduates' cognitive abilities. It proffers that certain non-cognitive personality traits like grit may influence the college readiness of SHS graduates in a non-Western context. The study used descriptive-correlation design to examine the relationship between grit and college readiness of 7,533 K-12 graduates enrolled in one public university in the north-eastern part of the Philippines. The results reveal that K-12 graduates admitted in the respondent-university are "mostly gritty," and a more significant proportion of them are college-unready. The students' grittiness is exemplified in the Filipinos' grit-related concepts such as sigasig (persistence of effort) and tiyaga (constancy in work) that are pursued because of their concept of "relational self." The test of the relationship shows that grit has a positive influence on the college readiness of SHS graduates. This finding proves that cognitive traits may not be a good factor in making SHS graduates admitted and successful in college. Essentially, some non-cognitive traits like grit are as vital as intellectual abilities in influencing college readiness. Given these results, it is imperative that educators and school administrators of the K-12 program need to develop further not only the intellectual abilities of the students under their care but also to give equal emphasis and development among elementary and secondary students as it is a valid and essential personal trait to better prepare them for a college education.
\end{abstract}

Keywords: Grit; College readiness; K-12 graduates; Constancy in work; Persistence of effort 


\section{Introduction}

Academic success has traditionally been associated with students' cognitive ability in various learning areas in the different academic levels. This concept has gained significant interest in various settings and has been pervasive through time. However, academic success is not a monopoly of a single factor but an influence of numerous interplaying factors. Grit, a personal attribute of arduous perseverance, is among the fundamental mechanisms in successfully achieving goals. Duckworth (2016) attached the word "grit" to passion and perseverance to achieve long-term goals. Reed and Jeremiah (2017) perceived it as a significant aspect of one's character as it uniquely grows and develops to contribute to an individual's success eventually. Through the years and across cultures, it has grown and expanded in parallel with various fields such as leadership, workplace, and education. Today, grit is highly encouraged in education because of its considerable contribution to students' academic success and achievements.

Since achievement springs from talent and effort, grittier learners who work harder, longer, and more deliberately produce enhanced success (Hogan and Wong, 2013; Kelly, Matthews \& Bartone, 2014). Because of the significant impact attached to grit in the academic milieu, it has been recognized as a major variable connected to different academic constructs such as academic motivation (Eskreis-Winkler, Shulman, Beal \& Duckworth, 2014), task values, and goal orientation (Muenks, Wigfield, Yang \& O'Neal, 2017), and learning strategies (Weisskirch, 2018). Previous studies laid that grit is an essential indicator of learners' better performance in the school setting and the real-world.

Another educational concept connected to grit is college readiness, which is the ability of the SHS graduates to be admitted and succeed in college (Conley, 2007; Barnes, Slate \& Rojas-LeBouef, 2010; Barnes \& Slate, 2013). Conventionally, college readiness has been proven to be related to grade point average, class rank, and scores in various academic tests or academic performances (Bridgeman, 1991; Kobrin, Patterson, Shaw, Mattern \& Barbuti, 2008). However, previous studies claim that it is also connected to non-cognitive factors such as student personality traits and family resources (Porter \& Polikoff, 2012). If any, few of the existing literature relate grit with college readiness; thus, this study.

It comes clear to record that students' grit and college readiness are two sides of the same coin. Hence, the paper aims to: (1) establish the connection between grit and college readiness among Filipino SHS graduates; (2) examine the applicability and usefulness of the grit scale in ascertaining the level of the perseverance of effort and consistency of interest of the Filipino students in accomplishing their long-term academic goals; and (3) provide an answer whether the K-12 graduates possess durable psychological resources like grit that could assist them to progress to tertiary education considering the additional two years of their schooling (Datu, 2015).

Given the foregoing context, this paper contributes to establishing the connection of grit in further explaining students' college readiness, which is limited in the pool of existing literature on non-cognitive research. This study 
aims to supply theoretical and pragmatic implications for both Philippine basic and higher education. Specifically, the study seeks to investigate the grit level and college readiness of the K-12 Filipino graduates and examine their relationship. The results will be valuable in providing vital data in refining admission policies, crafting transition interventions from basic education to tertiary level, and enhancing guidance services and other personal and learning support systems to students.

\subsection{Background of the Study}

In the Philippines, college readiness is a new concept brought about by the K-12 program's implementation. As tertiary education is one of the curricular exits of the program, educators, students, legislators, and other stakeholders are interested in determining SHS graduates' college readiness who pursue a college education. Along this line, the Commission on Higher Education (CHED) created the College Readiness Standards (CRS) in 2011, which defines the competencies that graduates of the K-12 Program need to master in the General Education Courses (GEC) to guarantee continuity of the competencies acquired from the K-12 curriculum. The purpose of creating the CRS is to minimize the remediation interventions among Higher Education Institutions (HEIs) and to measure up with international quality standards (CHED En Banc Resolution No. 298-2011). The CRS has seven (7) learning areas: English, Filipino, Literature, Mathematics, Science, Social Studies, and Humanities. These learning areas contain both content and performance standards. Content standards pertain to what students need to know, while performance standards refer to what they need to manifest through what they know.

Although no test is administered measuring the college readiness of the Filipino K-12 graduates, the Department of Education (DepEd) has conducted the Basic Educational Exit Assessment to Grade 12 students. The result of this test is exclusively for the consumption of the concerned agency purposely for enhancing its instructional delivery and crafting curricular interventions. HEIs could not use such a result as a basis for admitting SHS graduates. Thus, they are given the blanket authority to admit their students upon exercising their academic freedom. Given such a situation, they commonly use college admission tests, which may be teacher-made or standardized tests. These tests measure different competencies that may not be aligned with the CRS.

\subsection{Purpose of the Study}

In establishing the link between grit and college readiness shifts the paradigm to the understanding that college readiness is predicted beyond cognitive measures such as high school grade point average, SAT, and ACT (Duckworth et al., 2007; Duckworth, Quinn \& Tsukayama, 2012; Hiss \& Franks, 2014; Nasim et al., 2005). However, the caveat is that cognitive measures are still the primary factors predicting academic success in college. Non-cognitive factors such as character traits and psychosocial constructs are considered additional factors that may facilitate college readiness.

Given the foregoing context, this study examines the correlation between grit and college readiness among Filipino K-12 graduates, which addresses this 
concept's scarce literature, especially in the Philippines. The grit level in this study is measured in two (2) dimensions propounded by Duckworth et al. (2007), namely perseverance of effort (PE) and consistency of interest (CI). On the other hand, the college readiness, in this study, is a three-dimensional construct composed of (a) advancement and mastery of the entry competencies defined in the CRS; (b) ability to be admitted in college; and (c) ability to pass the GEC without remediation. Operationally, these constructs are all measured in the College Readiness Test (CRT), which is an achievement test anchored on the Philippine College Readiness Standards (CRS). The CRT measures content and performance standards along with the seven (7) learning areas. Figure 1 below presents the conceptual paradigm of the study consisting of the independent and dependent variables.

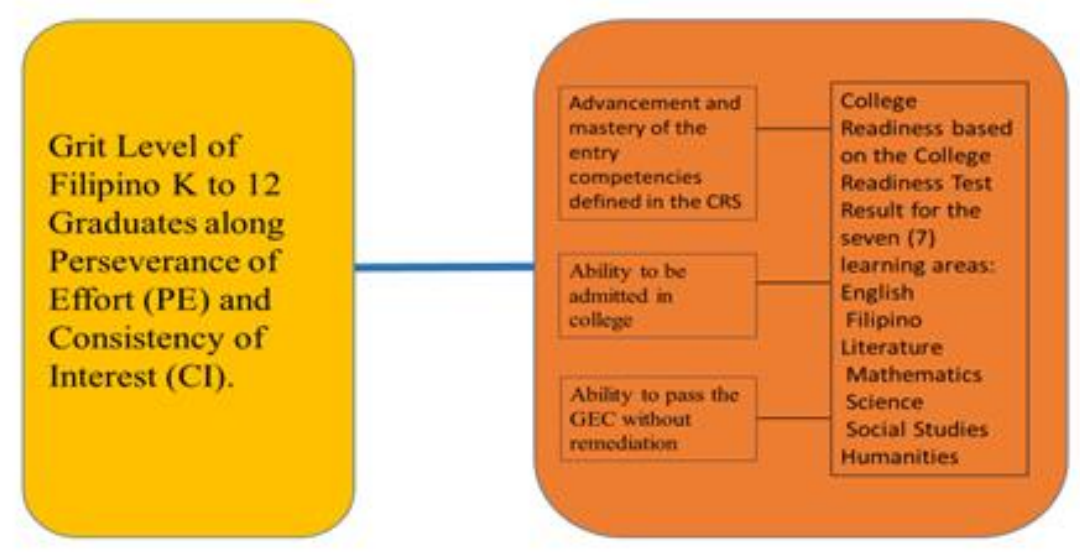

Figure 1. Conceptual Paradigm of the Study

\section{Related Literature}

\subsection{Understanding Grit as a Psychological Construct}

Grit, also called "gumption" (Przystas, 2016), pertains to the passion and perseverance essential to achieve long-term goals (Duckworth et al., 2007). It is a personal trait common among most achieving and successful individuals (Bashant, 2014). In a more specific sense, it is recognized as the "unshakable" long-term accomplishment of goals despite challenges and setbacks (Duckworth \& Gross, 2014).

Further, Duckworth (2016) creates the formula that talent plus effort equals skill, while skill plus effort turns into achievement. Regarding the fact that grit matures over time together with life experiences, several psychological assets help develop it, namely, interest or passion, practice or continuous improvement, purpose, and hope after challenges and failures. When these are combined with hard work, they become formidable psychological resources (Reed \& Jeremiah, 2017).

Fundamentally, grit is a multifaceted construct as it is a trait-level personality. While it is very much akin to conscientiousness, Duckworth et al. (2007) came up with a two-factor construct consisting of the perseverance of effort (PE) and 
consistency of interest (CI). PE denotes one's ability to continue and endure efforts amidst life's odds or setbacks. At the same time, CI refers to staying focused on the goals at hand over a long period and working hard to accomplish it (Duckworth et al., 2007). Between the two dimensions, Alhadabi and Karpinski (2019) claimed that perseverance of effort has a stronger influence on academic achievement than the consistency of interest.

\subsection{Grit in the Philippine Context}

Since grit is generally a western construct, its adoption in the Philippines raises potential and critical issues on its applicability and generalizability in a collectivist setting like the Philippines. The emphasis of this is essential because the society's culture is a significant shaper of an individual's psychological construct (King \& McInerney, 2014), which means that grit may come in diverse forms based on cross-cultural differences.

Among Filipinos, grit is conceptually related to sigasig (persistence) and tiyaga (constancy in work). Sigasig is the ability to go forward by force or by pushing or pressing hard to accomplish something. On the other hand, tiyaga is the ability to show diligence, industry, and zeal to pursue one's goals. Unlike the western personality trait, which emphasizes individuality, the Filipinos' concept of grit is not performed for individualistic reasons or purposes. Instead, it is pursued in relation to kapwa (others), which is not interpreted as 'other person' but 'together with the person' (Reyes, 2015). Thus, Filipino students are more inclined to pursue academic goals based on their purpose in maintaining and preserving their relationship with their family members, friends, and other significant others. Filipino youth value education, and they consider it to have personal relevance in shaping their academic aspirations and achievement (Bernardo, 2003).

\subsection{College Readiness as an Academic Construct}

College readiness is a concept that ascertains the fitness of SHS graduates to enter college, considering that a high school diploma does not guarantee and exhibit sufficient college preparation (Porter \& Polikoff, 2012). Using Conley's (2007) framework, the elements of college preparation include (a) knowledge of content; (b) application of content; and (c) cognitive strategies. These elements are construed holistically and should not be taken singly or separately because they constitute an interplay of factors necessary to hurdle the challenges of college education (Conley, Aspengren, Stout \& Veach, 2006).

Measuring college readiness has been a challenging task in most countries, which paved the way for its multiple measures (Leonard, 2013). Through the years, college readiness meant differently to different people depending on the context and the index to which it is based. Conventionally, grade point average (GPA) has been used as a predictor of college readiness (Camara \& Echternacht, 2000). Other predictors include class rank and scores in various academic tests (Bridgeman, 1991; Kobrin, Patterson, Shaw, Mattern \& Barbuti, 2008) and rigorous workload (Greene \& Foster, 2003). In the USA, most universities still rely on the use of standardized tests like the Scholastic Aptitude Test (SAT) and American College Test (ACT) and other questionnaires or checklists in predicting the college readiness of its students. This fact suggests that 
standardized tests are better measures in ascertaining the students' preparation for and chances of succeeding in college education (Landmark College, 2009). In conjunction with high school grade point average, standardized test results have high predictive value to college success (Sparkman, Maulding \& Roberts, 2012). Moreover, admission offices in some universities and colleges use holistic review by using a mix of cognitive traits, personal qualities, and behavioral measures in rating each college applicant (Rigol, 2003), which has predictive value for academic success in college.

\section{Methodology}

\subsection{Research Type and Participants}

The study employed descriptive-correlation design as it examined the relationship between the respondents' grit and college readiness. Employing a descriptive correlational design effectively describes two or more variables and shows their associations but not necessarily presenting their cause and effect (Sousa et al., 2007; Williams, 2007).

The respondents of the study were the first-year students enrolled in the respondent-university for SY 2019-2020. Among 8,601 first-year enrolled students, complete enumeration was employed among the K-12 graduates, constituting 7,533 (88\%) of the entire first-year student population. Graduates of Alternative Learning System (ALS) and the Revised Basic Education Curriculum (RBEC) were not included in the study because the competencies developed by their curricula are different from the $\mathrm{K}-12$ program. The respondents were distributed in the eight (8) campuses of the university, as shown in Figure 2 below:

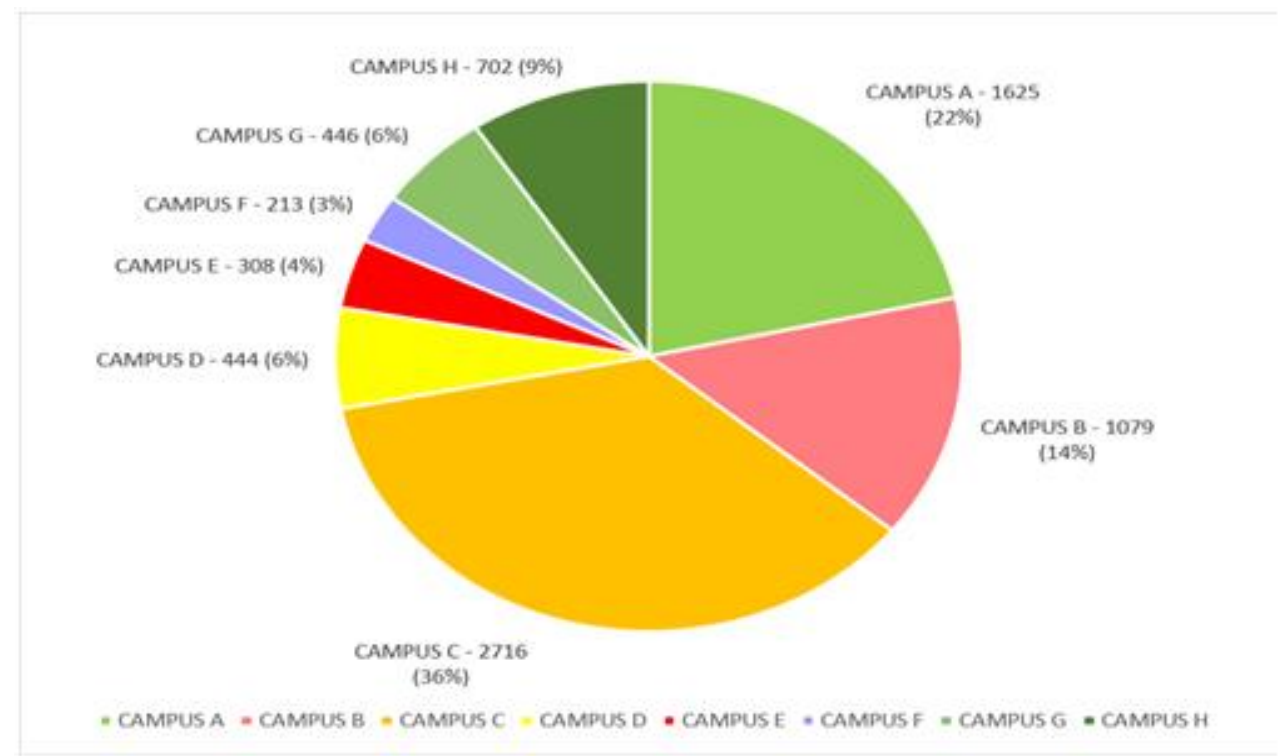

Figure 2. Frequency and Percentage Distribution of the Respondents by Campus 


\subsection{Instrument}

The Grit-Scale being developed by Duckworth et al. (2007) was utilized to determine the respondents' self-reported grit levels. It measures the extent to which the students can maintain focus, interest, and perseverance in obtaining long-term goals. It comes in a 12-item statement rated as 1-5 with $1=$ not at all like me to 5 = very much like me. It also has two (2) dimensions, namely, the perseverance of effort (PE) and consistency of interest (CI). The test's internal consistency is high, as it ranges from 0.77 to 0.90 based on previous studies (Duckworth et al., 2007; Duckworth \& Quinn, 2009). In this scale, no sub-score is reported because only the overall grit score is considered. Although the Gritscale is self-scored, the psychometricians nonetheless scored the said test for better analysis.

The respondents' college readiness was measured using the CRT, a criterionreferenced, contextualized, and gender-sensitive test, developed and validated by the Project Research Team of the Discovery and Applied Research and Extension Trans/interdisciplinary Opportunities (DARE TO) Research Grant. It has 200-items measuring learning competencies along with the seven (7) learning areas. The CRT measures the content with 30\% and the performance standards with $70 \%$. The content standards determine knowledge and comprehension while performance standards ascertain application, analysis, evaluation, testing assumptions, hypotheses, and relevant information. Furthermore, the CRT has 65.64 difficulty index, 0.22 discrimination index, $68.91 \%$ distractor efficiency, and $\mathrm{r}=0.798$ inter-item consistency.

\subsection{Procedures}

The administration of the two (2) tests was done after securing permission from the university authorities. An orientation on the ethical standards and protocols was given to the team members and all test administrators to abide by test administration standards and ethics. The free and prior informed consent form was developed and distributed to the respondents before the test administration. The CRT and Grit Scale were administered in the morning and afternoon, respectively. Both tests were administered, checked, and scored by the registered guidance counselors and psychometricians.

\subsection{Data Analysis}

The Grit and CRT results were analyzed using descriptive statistics (frequency, percentage, mean, and standard deviation). SPSS version 24.0 was used to analyze the data. In interpreting the grit result, the following 5-point Likert Scale was used:

Table 1. Arbitrary Scale for the Interpretation of the Grit Score

\begin{tabular}{|l|l|}
\hline \multicolumn{1}{|c|}{ Range } & \multicolumn{1}{c|}{ Interpretation } \\
\hline $4.2-5.00$ & Extremely Gritty \\
\hline $3.4-4.1$ & Mostly Gritty \\
\hline $2.6-3.3$ & Somewhat Gritty \\
\hline $1.8-2.5$ & Not Much Gritty \\
\hline $0.2-1.7$ & Not at All Gritty \\
\hline
\end{tabular}


Since the overall grit score is only considered, students with higher scores (composed of PE and CI) tend to be stronger learners. They are likely to be less demotivated in times of challenges and adversities. They, too, are more inclined to strategize and sustain positive behavior to achieve their goals. Concerning the CRT, students who obtained at least 100 correct responses from the 200-items were considered college-ready (Tamayao et al., 2020). Finally, Pearson r was used in ascertaining the relationship between grit and college readiness.

\section{Results}

\subsection{Grit Level of the Filipino K-12 Graduates as Revealed by the Grit Scale}

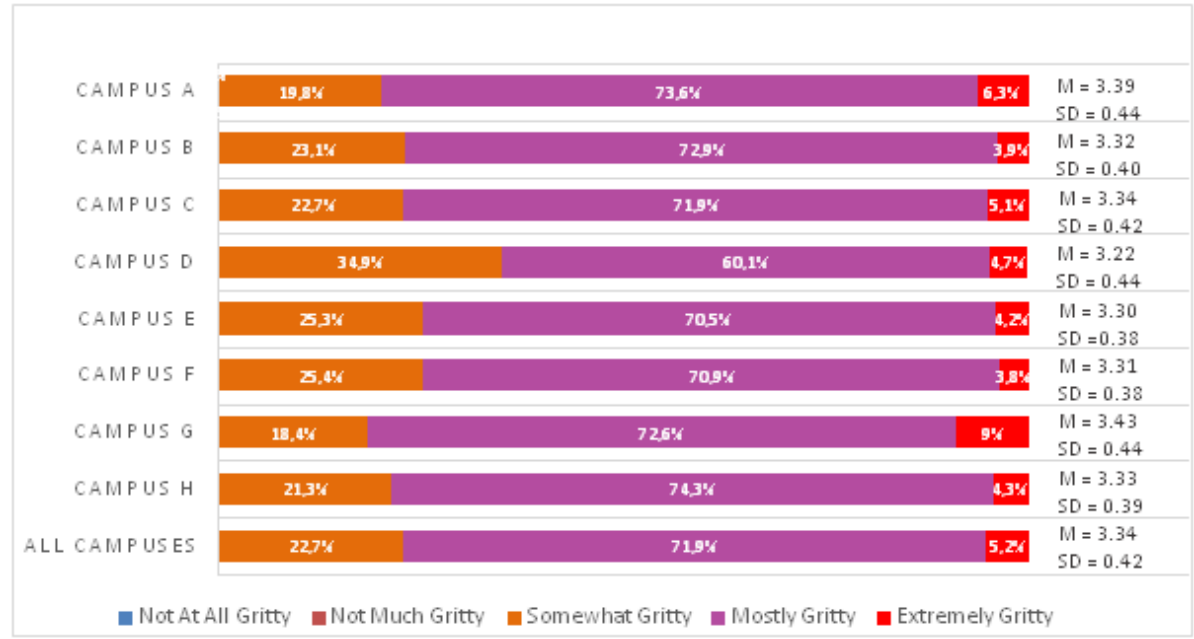

Figure 3. Grit Level of the Respondents by Campus

Figure 2 shows that generally, the respondents across campuses are 'mostly gritty' $(71.9 \%)$, which indicates their high tendency to maintain focus and interest and persevere in obtaining long-term goals. Moreover, they tend to work strenuously towards challenges and sustain effort and interest over the years despite failure, adversity, and plateaus in progress. A further perusal of the data indicates that Campus G obtained the highest grit score $(9 \%)$, and Campus $\mathrm{F}$ registered the lowest grit score $(3.8 \%)$

\subsection{College Readiness of the K-12 Graduates as Revealed by the CRT Results}

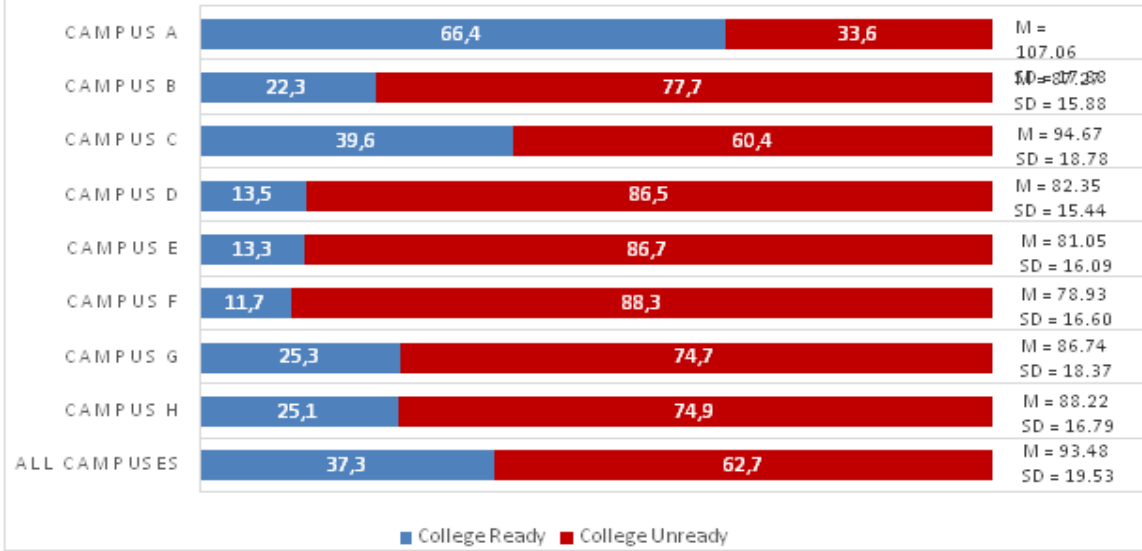

Figure 4. College-ready and College-unready K-12 Graduates 
As reflected, a greater proportion of college-unready students $(62.7 \%$ versus $37.3 \%$ college-ready students) have been admitted to the respondent-university. This result implies that only $2 / 5$ of the first-year K-12 graduates enrolled in the university are ready for college. Using the passing score of 100, the CRT's university-wide mean score is 93.49 , which is way below the acceptable passing score. The $37.3 \%$ of college-ready students are the ones who have acquired mastery of the competencies set in the CRS and have a greater possibility to hurdle the GEC without remediation.

A closer look at the data illustrates that the greatest number of college-ready students were admitted to Campus A (1,078 or $66.3 \%)$. In comparison, the smallest number of college-ready students (25 or $11.7 \%$ ) were admitted in Campus F. The result of the CRT also reveals that all campuses have a bigger number of college-unready students except for Campus A. These findings reveal that most campuses have admitted students who tend to have low chance to succeed in GEC. Further, Campus F needs to craft and implement immediate transition intervention measures considering that it registered the lowest total mean score in the CRT (78.93).

\subsection{Correlation between Grit and College Readiness}

Table 2. Correlation Between of Grit and College Readiness

\begin{tabular}{|l|c|c|}
\hline \multicolumn{1}{|c|}{ Parameters } & Grit Score & \\
\hline & $\begin{array}{l}\text { Correlation } \\
\text { Coefficient }\end{array}$ & P-Value \\
\hline $\begin{array}{l}\text { College Readiness } \\
\text { Test Score }\end{array}$ & $.107^{* *}$ & $<0.001$ \\
\hline \multicolumn{2}{|c|}{ ** Correlation is significant at the 0.01 level (2-tailed) }
\end{tabular}

Table 2 presents that grit is highly correlated with the respondents' CRT scores, as reflected in the computed r-value of .107 at a 0.01 level of significance. This finding means that grit plays a significant influence on the college readiness of the respondents. Students with high grit scores tend to score higher in the CRT and vice versa. Hence, grittier students are more able to master the entry competencies defined in the CRS. They, too, tend to have shown a higher potential to be admitted in college, and they have more likelihood to pass the GEC without remediation.

\section{Discussion}

The results reveal that SHS graduates admitted in the respondent-university are "mostly gritty" as they show the consistency of interest and perseverance of effort in realizing their academic aspirations in life. Amidst challenging situations, these students demonstrate persistence in accomplishing their lifelong aspirations in college or even beyond. Moreover, these "mostly gritty" students have the likelihood to demonstrate mastery of the content and performance standards set in the CRS in the sense that they can use their grit in acquiring the essential knowledge, skills, and values necessary for them to be admitted and to succeed in college. The finding affirms numerous researchers 
claiming that the students' ability to persevere in times of challenges and adversities, especially in the academic setting, plays a significant role in determining their academic success and beyond (De Beer \& van Heerden, 2017; Duckworth, 2016, Grant Halvorson, 2012; Hattie, 2009).

Although grit is a borrowed western construct in the study, Filipinos have always been known for their cultural trait as being masigasig (persistent) and matiyaga (diligent). Rungduin and Reyes (2016) highlight this as one of the Filipino learners' developmental characteristics and values. Fundamentally, Filipinos' persistence and diligence in accomplishing long-term goals emanate from their relational will, that is, the ability to contribute primarily to their families' well-being and significant others. For example, students in Philippine universities value and pursue long-term educational goals, not for personal motives but mainly for family reasons, i.e., fulfilling their dutiful and familial obligation (Reyes \& Galang, 2009). The show of one's grittiness demonstrates the Filipinos' likelihood of being relationship-oriented as their loob (better understood as relational will) seeks to preserve and strengthen their human relationships. The Filipinos' concept of grit goes beyond the focus on self; instead, it is always pursued in relation to their kapwa - a shared identity with others - which according to Enriquez (1992), is a reflection of the Filipino's concept of pagkakaisa, known to be their supreme level of interpersonal relationship. The value given by Filipino learners to their kapwa starts at an early age of their socialization (Rungduin \& Reyes, 2016), which helps in the development of their relational self as proven by previous studies (Ching et al., 2014; Datu, 2015; Grimm, Church, Katigbak \& Reyes, 1999). When they persevere in their effort and maintain consistency of focus in achieving their long-term goals, it is always done to secure their family's interest and welfare and significant others. In so doing, they can preserve and strengthen their relationship, which is an essential index of their success and purpose in life.

The CRT result illustrates that a greater proportion of students enrolled in the respondent-university are college-unready. While these students have been admitted to the university, the finding indicates that they are less likely to succeed in their GEC and perhaps their chosen academic programs. As they are college-unready, they may also experience difficulty in accomplishing their college coursework. This college unreadiness may be accounted for because they fall short in acquiring the necessary content and performance standards in the seven (7) learning areas identified in the CRS. The lack of college readiness of the respondents affirms the numerous studies showing that the Filipino students have the low ability in science and mathematics; they are ranked 79th in reading (Paris, 2019); and they fall short in demonstrating literacy and numeracy skills, particularly in the English language (Philippine Institute of Development Studies [PIDS], 2020).

The test of the relationship shows that grit is positively correlated with college readiness. Grittier students are more able to show college readiness than their counterparts. These students are more likely to demonstrate persistence in acquiring content and performance standards, which are essential in accomplishing their long-term educational goals and college ambitions. In this 
regard, the finding affirms Mason (2018) assertion that grit is a valid personal trait in explaining students' success in college learning. Thus, grit must be nurtured or reinforced in basic education (Alhadabi \& Karpinski, 2019; Christopoulou et al., 2018) as it enhances students' potentials and facilitates positive educational outcomes, especially on college readiness.

\section{Conclusion}

It is a commonly held assumption that students' cognitive capacities influence college readiness. However, this paper argues that non-cognitive trait-like grit plays a crucial and indispensable role in SHS Filipino graduates' college readiness. Such an argument is anchored on the belief that college readiness is not a monopoly of a single factor but a confluence of numerous interplaying factors. This study affirms that indeed grit has a positive influence on the college readiness of SHS graduates. It proves that cognitive traits may not be a sufficient factor in explaining college readiness. Essentially, some non-cognitive traits like grit are as vital as intellectual abilities in influencing college readiness. Given these results, it is essential that educators in the K-12 program need to further develop not only the intellectual abilities of the students under their care. Grit needs to be enhanced and be given equal emphasis and development among elementary and secondary students to better prepare them for a college education. This can be carried out by strengthening the homeroom program, guidance services, and student organizations, as well as co-curricular and extracurricular activities in the basic education.

\section{Limitations of the Study and Further Research}

The Grit Scale and the CRT, which were utilized in the study, are still in the process of undergoing further validity tests. In this regard, the results obtained may not present greater generalizability in the Philippines' different HEIs and geographical locations. However, their use bridges the gap on the dearth of literature and studies about grit and college readiness among Filipino K-12 graduates. Although grit is a multifaceted concept, it is limited to two dimensions: consistency of interest and perseverance of effort. On the other hand, college readiness is limited to students' ability to demonstrate advancement and mastery of the CRS's entry competencies, ability to be admitted in college, and ability to pass the GEC without remediation. The results will be the basis for conceptualizing a framework explaining the nexus of grit and college readiness among Filipino K-12 graduates in the Philippine context. Furthermore, a local norm may be developed to establish the validity of the Grit Scale in the Philippine context and to include its translation in the Filipino languages.

\section{Conflict of Interest}

As a funded research project by CHED, the authors declare no conflict of interest in the study, considering that ethical standards and relevant research protocols were strictly followed.

\section{Acknowledgment}

The authors express their heartfelt gratitude to the CHED Central Office for funding the project through the Discovery Applied Research and Extension 
towards Transdisciplinary/ Multidisciplinary Opportunities (DARE TO). Special thanks is accorded to CHED Commissioner Lilian de las Llagas, President Urdujah Tejada, DARE TO K-12 Staff, and the technical committee members for their indefatigable efforts in accomplishing this research.

\section{References}

Alhadabi, A., \& Karpinski, A. (2019). Grit, self-efficacy, achievement orientation goals, and academic performance in University students. International Journal of Adolescence and Youth, 25(1), 519-535. https:// doi.org/10.1080/02673843.2019.1679202

Barnes, W., Slate, J., \& Rojas-LeBouef, A. (2010). College readiness and academic preparedness: The concepts? Current Issues in Education, 13(4), 1-28. Retrieved from http://cie.asu.edu/

Barnes, W., \& Slate, J. (2013). College-readiness is not one-size-fits-all. Current Issues in Education, 16(1), 1-13. Retrieved from https://pdfs.semanticscholar.org/04cd/2527d0dfc69cbc20cc5bffad4d32ddf9484 e.pdf

Bashant, J. (2014). Developing grit in our students: Why grit is such a desirable trait, and practical strategies for teachers and schools. Journal for Leadership and Instruction, 13(2), 14-17. Retrieved from https:// files.eric.ed.gov/fulltext/EJ1081394.pdf

Bernardo, A. (2003). Do Filipino youth really value education? Exploring Filipino adolescents" beliefs about the abstract and pragmatic value of education and its relationship to achievement goals and learning strategies. Philippine Journal of Psychology, 36(1), 49-67.

Bridgeman, B. (1991). Essays and multiple-choice tests as predictors of college freshman GPA. Research in Higher Education, 32, 319-331. https://doi.org/10.1007/BF00992895

Camara, W. J., \& Echternacht, G. (2000). The SAT I and high school grades: Utility in predicting success in college (Research Notes RN-10). The College Board, Office of Research and Development. Retrieved from http://research.collegeboard.org/sites/default/files/publications/2012/7

CEB Resolution No. 298-2011. College readiness standards. Retrieved from http://www.digigogy.com/uploads/4/5/6/7/4567766/cmo-20s2013_appendix_c.pdf

Ching, C. M., Church, A. T., Katigbak, M. S., Reyes, J. A. S., Tanaka-Matsumi, J., Takaoka, S., Zhang, H., Shen, J., Arias, R., Rincon, B. C., \& Ortiz, F. (2014). The manifestation of traits in everyday behavior and affect: A five-culture study. Journal of Research in Personality, 48, 1-16. https:// doi.org/10.1016/j.jrp.2013.10.002

Christopoulou, M., Lakioti, A., Pezirkianidis, C., Karakasidou, E., \& Stalikas, A. (2018). The role of grit in education: A systematic review. Psychology, 9, 2951-2971. https://doi.org/10.4236/psych.2018.915171

Conley, D. T. (2010). College and career ready: Helping all students succeed beyond high school. San Francisco, CA: Jossey-Bass. https://doi.org/10.1002/9781118269411

Conley, D. T. (2007). Toward a more comprehensive conception of college readiness. Eugene, OR: Educational Policy Improvement Center. Retrieved from https://docs.gatesfoundation.org/documents/collegereadinesspaper.pdf

Conley, D. T., Aspengren, K., Stout, O., \& Veach, D. (2006). College Board Advanced Placement best practices course study report. Eugene, OR: Educational Policy Improvement Center. https://www.inflexion.org/college-board-advancedplacement-best-practices-course-study/ 
Datu, J. A. D. (2015). Validating the revised self-construal scale in the Philippines. Current Psychology, 34, 626-633. https://doi.org/10.1007/s12144-014-9275-9

Datu, J. A. D., Valdez, J. P. M., \& King, R. B. (2016). The Successful Life of Gritty Students: Grit Leads to Optimal Educational and Well-Being Outcomes in a Collectivist Context. In R. King \& A. Bernardo (eds.), The Psychology of Asian Learners. Singapore: Springer. https://doi.org/10.1007/978-981-287-576-1_31

De Beer, M., \& van Heerden, A. (2017). The psychological coping, learning potential, and career profiles of operational force military candidates. Journal of Psychology in Africa, 27 (1), 33-40. https:/ / doi.org/10.1080/14330237.2016.1250427

Duckworth, A. L. (2016). Grit: The power of passion and perseverance. Scribner: New York, NY.

Duckworth, A. L., \& Gross, J. (2014). Self-control and grit: Related but separable determinants of success. Current Directions in Psychological Science, 23(5), 319-325. https://doi.org/10.1177/0963721414541462

Duckworth, A. L., \& Quinn, P. D. (2009). Development and validation of the Short Grit Scale (GRIT-S). Journal of Personality Assessment, 91(2), 166-174. https://doi.org/10.1080/00223890802634290

Duckworth, A. L., Peterson, C., Matthews, M. D., \& Kelly, D. R. (2007). Grit: Perseverance and passion for long-term goals. Journal of Personality and Social Psychology, 92(6), 1087-1101. https://doi.org/10.1037/0022-3514.92.6.1087

Duckworth, A. L., Quinn, P. D., \& Tsukayama, E. (2012). What No Child Left Behind leaves behind: The roles of IQ and self-control in predicting standardized achievement test scores and report card grades. Journal of Educational Psychology, 104(2), 439-451. https://doi.org/10.1037/a0026280

Enriquez, V. (1992). From colonial to liberation psychology. Quezon City: The University of the Philippines Press.

Eskreis-Winkler, L., Shulman, E. P., Beal, S., \& Duckworth, A. L. (2014). The grit effect: Predicting retention in the military, the workplace, school, and marriage. Frontiers in Psychology, 5(36), 1-28. https://doi.org/10.3389/fpsyg.2014.00036

Grant-Halvorson, H. (2012). Succeed: How we can reach our goals. New York, NY: Hudson Stress Press.

Greene, J. P., \& Forster, G. (2003). Public high school graduation and college readiness rates in the United States. New York, NY: Center for Civic Innovation, Manhattan Institute.

Grimm, S. D., Church, A. T., Katigbak, M. S., \& Reyes, J. A. S. (1999). Self-described traits, values, and moods associated with individualism and collectivism: Testing I-C theory in an individualistic (U.S.) and a collectivistic (Philippine) culture. Journal of Cross-Cultural Psychology, 30(4), 466-500. https:// doi.org/10.1177/0022022199030004005

Hattie, J. A. C. (2009). Visible learning: A synthesis of over 800 meta-analyses relating to achievement. New York, NY: Routledge.

Hogan, M., \& Wong, K. (2013). Grit and mindset: Do you have the grit to go the distance? Women Lawyers Journal, 98(3), 1-11. Retrieved from https://lowellmilkeninstitute.law.ucla.edu/wpcontent/uploads/2017/03/grit_toolkit_nawl_article.authcheckdam.pdf

Hiss, W. C., \& Franks, V. W. (2014). Defining promise: Optional standardized testing policies in American college and university admissions. Retrieved from https://www.luminafoundation.org/files/resources/definingpromise.pdf

Kelly, D. R., Matthews, M. D., \& Bartone, P. T. (2014). Grit and hardiness as predictors of performance among West Point cadets. Military Psychology, 26(4), 327-342. https://doi.org/10.1037/mil0000050 
King, R. B., \& McInerney, D. M. (2014). Culture's consequences on student motivation: Capturing cross-cultural universality and variability through personal investment theory. Educational Psychologist, 49(3), 175-198. http://dx.doi.org/10.1080/00461520.2014.926813

Kobrin, J. L., Patterson, B. F., Shaw, E. J., Mattern, K. D., \& Barbuti, S. M. (2008). The validity of the SAT for predicting first-year college grade point average (College Board Research Report No. 2008-5). New York: The College Board. Retrieved from http://professionals.collegeboard.com/profdownload/pdf/081718_RDRR_081017_Web.pdf

Landmark College. (2009). Landmark College's guide to assessing college readiness for parents of college-bound children with learning disabilities or AD/HD. Putney, Vermont: Landmark College.

Leonard, J. (2013). Maximizing college readiness for all through parental support. School Community Journal, 23(1), 183-202. Retrieved from https:// files.eric.ed.gov/fulltext/EJ1004338.pdf

Mason, H. D. (2018). Grit and academic performance among first-year university students: A brief report. Journal of Psychology in Africa, 28(1), 66-68. https:// doi.org/10.1080/14330237.2017.1409478

Muenks, K., Wigfield, A., Yang, J. S., \& O'Neal, C. R. (2017). How true is grit? Assessing its relations to high school and college students' personality characteristics, selfregulation, engagement, and achievement. Journal of Educational Psychology, 109(5), 599-620. https://doi.org/10.1037/edu0000153

Nasim, A., Roberts, A., Harrell, J., \& Young, H. (2005). Non-cognitive predictors of academic achievement for African Americans across cultural contexts. Journal of Negro Education, 74(4), 344-358. Retrieved from https:// psycnet.apa.org/record/2006-02229-005

Paris, J. (2019, December). The Philippines ranks among the lowest in reading, math, and science in the 2018 study. Rappler Philippines. Retrieved from https://rappler.com/nation/philippines-ranking-reading-math-science-pisastudy-2018

Philippine Institute for Development Studies. (2020). Some learners lack basic SHS competency. Development Research News. Retrieved from https:// pidswebs.pids.gov.ph/CDN/PUBLICATIONS/pidsdrn20-1.pdf

Porter, A., \& Polikoff, M. (2012). Measuring academic readiness for college. Educational Policy, 26(3), 394-417. https:// doi.org/10.1177/0895904811400410

Przystas, B. (2016). What does it mean to have grit? Retrieved from https://www.canr.msu.edu/news/what_does_it_mean_to_have_grit

Reed, L., \& Jeremiah, J. (2017). Student grit as an important ingredient for academic and personal success. Developments in Business Simulation and Experiential Learning, $44,252-256$.

Reyes, M. L., \& Galang, A.J. (2009). Motivational and social aspects of the Filipino college experience. Philippine Journal of Psychology, 42(2), 213-235. Retrieved from https://pdfs.semanticscholar.org/db1d/47a747e9a3d89407c8e87d31ed76f95a85 24.pdf

Reyes, J. (2015). Loób and Kapwa: An introduction to a Filipino Virtue Ethics. Asian Philosophy, 25(2), 148-171. http://dx.doi.org/10.1080/09552367.2015.1043173

Rigol, G. W. (2003). Admissions decision-making models: How US institutions of higher education select undergraduate students. New York: College Board.

Rungduin, T. T., \& Reyes, Z. Q. (2016). The Filipino learner: A socioemotional perspective. International Journal of Research Studies in Education, 5(4), 1-18. https://doi.org/10.5861/ijrse.2015.1329 
Salisu, I., Hashim, N., Mashi, M. S., \& Aliyu, H. G. (2020). Perseverance of effort and consistency of interest for entrepreneurial career success: Does resilience matter? Journal of Entrepreneurship in Emerging Economies, 12(2), 279-304. https:/ / doi.org/10.1108/JEEE-02-2019-0025

Sousa, V., Driessnack, M., \& Mendes, I. A. C. (2007). An overview of research designs relevant to nursing: Part 1: Quantitative research designs. Revista LatinoAmericana de Enfermagem, 15(3), 502-507. https://doi.org/10.1590/S010411692007000300022

Sparkman, L., Maulding, W., \& Roberts, J. (2012). Non-cognitive predictors of student success in college. College Student Journal, 46(3), 642-652. Retrieved from https://eric.ed.gov/?id=EJ996963

Tamayao, A., Vecaldo, R., Asuncion, J. E., Mamba, M., Paat, F. M., \& Pagulayan, E. (2020). Design and validation of the college readiness Test (CRT) for Filipino K12 graduates. International Journal of Higher Education, 9(2), 209-224. https://doi.org/10.5430/ijhe.v9n2p209

Weisskirch, R. S. (2018). Grit, self-esteem, learning strategies and attitudes and estimated and achieved course grades among college students. Current Psychology,37, 2127. https:/ / doi.org/10.1007/s12144-016-9485-4

Williams, C. (2007). Research methods. Journal of Business $\mathcal{E}$ Economics Research, 5(3), $65-$ 72. https://doi.org/10.19030/jber.v5i3.2532 